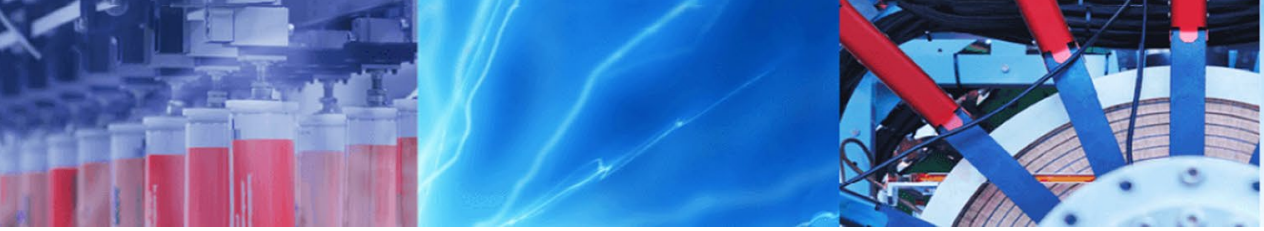

Research Article

\title{
Forward converter-based distributed global maximum power point tracking in partial shading conditions
}

\author{
Mustafa Engin Başoğlu' ${ }^{1}$ (1)
}

Received: 20 October 2019 / Accepted: 9 January 2020 / Published online: 21 January 2020

(c) Springer Nature Switzerland AG 2020

\begin{abstract}
Maximum power point tracking (MPPT) is an essential part of a photovoltaic (PV) power generation systems to obtain the possible biggest efficiency. In partial shading conditions (PSCs), distributed MPPT strategy is used to eliminate mismatching cases between PV modules and load. In this study, forward converter-based distributed MPPT approach is presented for small power module-level and submodule-level MPPT applications. First, operation principles of a forward converter are explained for an MPPT application. Then, performance of a forward converter is evaluated by perturb and observe (P\&O) algorithm for module-level and submodule-level MPPT systems in MATLAB/Simulink. Simulation results show that in module-level MPPT technique, forward converter cannot track global maximum power point (MPP) in some PSCs. On the other hand, submodule-level MPPT guarantees global MPPT (GMPPT). Average tracking efficiencies are calculated as $71.24 \%$ and $95.34 \%$ for module-level and submodule-level MPPT, respectively. That is, submodule-level MPPT outperforms module-level MPPT. On the other hand, submodule-level MPPT is more expensive solution since hardware requirements are very high compared with the module-level MPPT strategy.
\end{abstract}

Keywords Distributed MPPT · Forward converter · Perturb and observe algorithm · Submodule-level MPPT

\section{Introduction}

Distributed power generation has been very popular with the developments in renewable energy sources (RES). Integration of RES in a power generation system provides diversity of energy sources which increases the energy efficiency and proper energy management. In RESs, solar energy applications have very large power range changing from a few watts to a few giga watts. For example, solar energy can be used as a power plant level. On the other hand, solar energy can be used in a rooftop application which feeds home appliances in residential cases. In a small powered application, PV modules may be partially shaded due to the objects preventing solar irradiation received. In this kind of application, MPPT is not realized by a basic algorithm [1].
To achieve maximum efficiency from a PV module, power processing unit of a PV system is controlled by an MPPT algorithm [1]. There are several kinds of MPPT algorithms presented as a review study in [2]. P\&O technique, incremental conductance (IC) algorithm and constant voltage are basic of them which perform MPPT economically and with high efficiency. Furthermore, they have low software and hardware requirements. However, this kind of algorithms is suitable under uniform irradiance conditions. In multi-peak conditions, for example, under PSCs, they may fail at the local MPPs [3]. To overcome and eliminate this failure, a hybrid MPPT technique has been presented in [4]. First, power-voltage (P-V) curve of PV module is scanned. According to the scanning result, initial operation point, which is the vicinity of global MPP, is determined and power processing unit is operated at this point by a

Mustafa Engin Başoğlu, menginbasoglu@gumushane.edu.tr| ${ }^{1}$ Department of Electrical and Electronics Engineering, Faculty of Engineering and Natural Sciences, Gümüşhane University, Gümüşhane, Turkey. 
MPPT algorithm. Finally, P\&O is used to complete and finetune this operation point.

Forward converter is an improved and isolated buck converter topology. It is generally used in switch mode power supplies. If desired, forward converter can be used as a boost mode. However, buck mode is generally preferred in power electronics applications. Surprisingly, MPPT application of a forward converter has not been studied much. There are a few studies about forward converter-based micro-inverter [5-9]. A multiphase primary-parallel secondary series forward-based microinverter has been proposed for AC module applications. In this study, hardware-based improvement has been studied [5]. Single-stage grid-connected forward converterbased micro-inverter has been presented in [6]. It is aimed that unity power factor of injected power is transferred to the electrical grid Thus, power factor correction is realized. Furthermore, MPPT control is performed. In another study, a forward micro-inverter with power decoupling has been proposed in [7]. In this paper, operation principle of the proposed topology is studied deeply. Proposed topology has been verified by low-powered prototype. An improved micro-inverter topology containing dual switches forward and full-bridge converter has been presented in [8]. Theoretical analysis of the new converter topology is made. Performed analysis has been validated by $300-W$ powered experiment. In [9], it has been shown that active clamp forward converter performs worse than flyback converter in terms of transformer turns ratio and high voltage level. In order to eliminate sensing current resonance and rectifying diode recovery power loss, a parallel transformer configuration-based forward converter has been presented.

Forward converter can be used in distributed MPPT systems [10-12]. Since it has a transformer, voltage transformation feature provides flexible MPPT operation. For example, autotransformer forward-flyback converter has been proposed to eliminate negative mismatching effects of PV modules in [10]. New forward converter topology has been developed in [11]. A 240-W prototype converter has been implemented to validate this topology. In this circuit, power efficiency is about $91 \%$ owing to the zero voltage switching. Differential power processing (DPP) is one of the popular strategies to eliminate the unbalancing condition in PV systems. In [12], a DPP-based charged pump flyback-boost-forward converter configuration is designed. In this configuration, flyback is active when there is an unbalancing in loads. Therefore, partial power processing is realized and cost-effective solution is provided. Multi-input series-connected forward converter has been presented for solar- and wind-based RESs in [13]. Two forward converters are connected in series and use the same output inductor. They can operate simultaneously and individually depending on atmospheric conditions.
In this paper, performance of a forward converter is evaluated in module-level and submodule-level MPPT strategy which are two of the distributed MPPT strategies and commercially used technique in PV power optimizer devices. Advantages and disadvantages of two distributed MPPT techniques have been evaluated by some simulation studies performed in MATLAB/Simulink software. Organization of this paper continues as follows. In the next section, operation principle of the basic forward converter is presented for an MPPT application. Simulation results are given and analysed in Section III. In conclusion, prominent results of the study and future targets are listed briefly.

\section{Operation principles of forward converter}

Forward converter is an improved and isolated version of the buck converter. It has large usage area including switch mode power supplies and micro-inverter for AC module applications. In general, power level of a single switch forward converter is below $200 \mathrm{~W}$ [14]. Furthermore, it proposes a galvanic isolation and power transmission is realized perfectly due to the full transformer utilization. A typical forward converter consists of a power switch, two diodes, a transformer, an output capacitor and filter inductor. Furthermore, to discharge magnetizing energy in each cycle, tertiary winding and a freewheeling diode are added to the primary side of the transformer. A typical single switch forward converter is presented in Fig. 1.

Basic version of the forward converter has single switch. To explain the operation principle of a forward converter topology, two operation intervals should be analysed. These operation intervals are switch on and switch off. When the power switch is turned on, voltage of primary winding is equal to voltage of PV module. Energy from the PV module is transferred to the secondary side of the transformer. In this period, diode $D_{1}$ is forward biased and current of output inductor increases linearly. In other words, energy is stored in the output inductor. At the same time, voltage of secondary winding is equal to primary winding voltage multiplied by the transformer turns ratio.

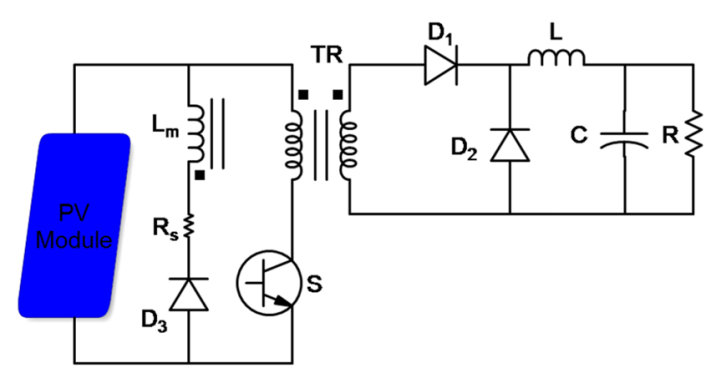

Fig. 1 Basic form of a forward converter with PV module 


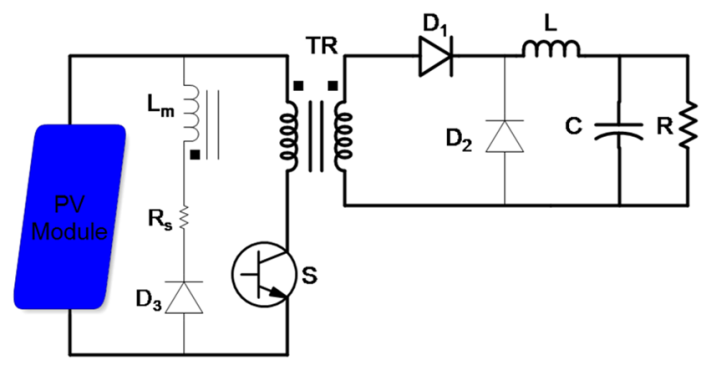

Fig. 2 On state condition of power switch in a forward converter

At the secondary side of the transformer, voltage seen in diode $D_{3}$ is negative since diode $D_{3}$ is reverse biased [14]. When the switch is on, voltage of primary and secondary winding, current variation of magnetizing inductor, Lm, current variation of the output inductor and relationship between input voltage and output voltage are calculated as given in Eqs. (1-5). Active components of the forward converter during switch on are presented in the circuit in

Fig. 2.

$V_{\mathrm{Lp}}=V_{\mathrm{PV}}$

$V_{\mathrm{Ls}}=V_{\mathrm{PV}} \frac{N_{\mathrm{S}}}{N_{\mathrm{P}}}$

$\Delta i_{\mathrm{Lm}}=\frac{V_{\mathrm{PV}} D T}{L_{\mathrm{m}}}$

$\Delta i_{\mathrm{L}}=\frac{\frac{V_{\mathrm{PV}} N_{\mathrm{P}}}{N_{\mathrm{S}}}-V_{\mathrm{O}}}{L} D T$

$V_{\mathrm{O}}=V_{\mathrm{PV}} D \frac{N_{\mathrm{S}}}{N_{\mathrm{P}}}$

In Eqs. (1-5), $V_{\mathrm{Lp}}$ is the voltage of primary winding, $V_{\mathrm{PV}}$ is the voltage of $\mathrm{PV}$ module or $\mathrm{PV}$ submodule, $V_{\mathrm{Ls}}$ is the voltage of secondary winding, and $V_{O}$ is the output voltage of the forward converter. $N_{\mathrm{P}}$ and $N_{\mathrm{S}}$ are the number of primary and secondary windings, respectively. $\Delta i_{\mathrm{Lm}}$ and $\Delta i_{L}$ are the current ripple of magnetizing inductance and filter inductor, respectively. $L_{\mathrm{m}}$ and $L$ are the magnetizing inductance and output inductor, respectively. $D$ is the duty ratio, and $T$ is the switching period [15].

When the power switch is turned off, energy transfer from the PV module is interrupted. In the switch off interval, voltage of primary winding is equal to zero. Magnetizing energy saved in the leakage inductance of the primary winding is wasted in the resistor which is connected in series to $L_{m}$. In a switch mode power supply application, this power can be recovered by transferring back to the source. Diode $D_{3}$ is forward biased during switch off which creates a current path to prevent the saturation of the magnetic core. In the secondary side of the transformer, polarity of the secondary winding gets reversed. So diode $D_{1}$ is reverse biased. Current of output inductor continues to flow through diode $\mathrm{D}_{2}$, and load is fed by the output capacitor and filter inductor. It is theoretically assumed that output voltage is constant when the switch is turned on and turned off. Because, output capacitance is high enough to prevent significant voltage ripple. During switch off, current variation of the magnetizing inductor is same as in Eq. (3). On the other hand, output inductor discharges in switch off interval. Current variation of output inductor is calculated as in Eq. (6) [15]. In Fig. 3, active component of the forward converter during switch off interval is prevented.

$\Delta i_{\mathrm{L}}=\frac{-V_{\mathrm{C}}}{L}(1-D) T$

Forward converter can be a choice for MPPT operation in module-level power optimizers. Unlike the basic version of the buck converter topology, ratio of windings number provides large voltage range between input and output voltages. Besides that, typical power range of forward converter is convenient for module-level PV power optimizers. In a MPPT application, converter, as a power processing unit, is an interface between PV module and load. This converter is used for impedance matching. For the forward converter, relationship between equivalent resistance of PV module and load resistance is given in Eq. (7) $[16,17]$.

$R_{\mathrm{PV}, \mathrm{MPP}}=\frac{R_{\text {Load }}}{D^{2}}\left(\frac{N_{\mathrm{P}}}{N_{\mathrm{S}}}\right)^{2}$

In Eq. (7), $R_{\mathrm{PV}, \mathrm{MPP}}$ is the equivalent resistance seen from PV module. $R_{\text {Load }}$ is the value of load resistance. $R_{\mathrm{PV}, \mathrm{MPP}}$ is the ratio of maximum power voltage $\left(V_{\mathrm{mpp}}\right)$ to maximum power current $\left(I_{\mathrm{mpp}}\right)$. Value of $R_{\mathrm{PV}, \mathrm{MPP}}$ depends on the type of PV module, power level and environmental conditions.

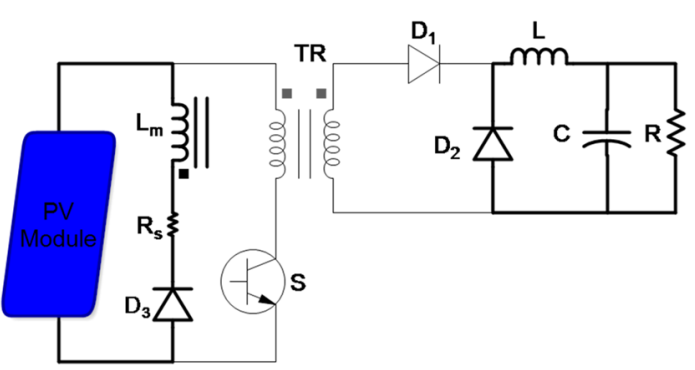

Fig. 3 Off state condition of power switch in a forward converter 
To obtain maximum available power, impedance matching between $R_{\mathrm{PV}}$ and $R_{\text {Load }}$ should be properly realized. Otherwise, the desired level of power cannot be obtained from the PV module.

\section{Simulation results}

In this section, module-level and submodule-level MPPT performance of the forward converter has been evaluated for two different PSCs. A crystalline PV module containing three bypass diodes is used in simulations. Main specifications of this PV module are listed in Table 1. In module-level MPPT, one forward converter is connected to the PV module. On the other hand, three forward converters are used in submodule-level MPPT system. In this system, MPPT is realized by submodule level. Each converter realizes its own MPPT with P\&O algorithm. Main parameters of the forward converter and some features of the P\&O algorithm are shown in Table 2. Simulink model of the submodule-level MPPT approach is illustrated in Fig. 4. In this approach, MPPT operations are executed independently in three different forward converters with $\mathrm{P} \& \mathrm{O}$ algorithm. Therefore, MPP tracking times of three submodules may be different. Since each converter realizes its own MPPT, P-V curves of each submodule must not be multi-peak structure. As a result, tracking of MPP is performed at the highest efficiency using a simple MPPT algorithm.

In the first PSC, irradiance values received by submodules are $300 \mathrm{~W} / \mathrm{m}^{2}, 600 \mathrm{~W} / \mathrm{m}^{2}$ and $1000 \mathrm{~W} / \mathrm{m}^{2}$. In

Table 1 Specifications of the PV module [18]

\begin{tabular}{ll}
\hline Bosch PV module c-Si M 48 & Value \\
\hline Short-circuit current & $8.5 \mathrm{~A}$ \\
Open-circuit voltage & $28.9 \mathrm{~V}$ \\
Maximum power voltage & $23.4 \mathrm{~V}$ \\
Maximum power current & $7.9 \mathrm{~A}$ \\
Maximum power & $180 \mathrm{~W}$ \\
Bypass diodes & 3 \\
\hline
\end{tabular}

Table 2 Specifications of the forward converter and P\&O algorithm

\begin{tabular}{ll}
\hline Parameter & Value \\
\hline Input/output capacitor & $1000 \mu \mathrm{F} / 100 \mu \mathrm{F}$ \\
Magnetizing inductance & $4 \mathrm{mH}$ \\
Windings turns ratio $\left(N_{\mathrm{p}} / N_{\mathrm{S}}\right)$ & $1 / 4$ \\
Switching frequency & $25 \mathrm{kHz}$ \\
Duty step/sample time & $0.1 \% / 1 \mathrm{~ms}$ \\
\hline
\end{tabular}

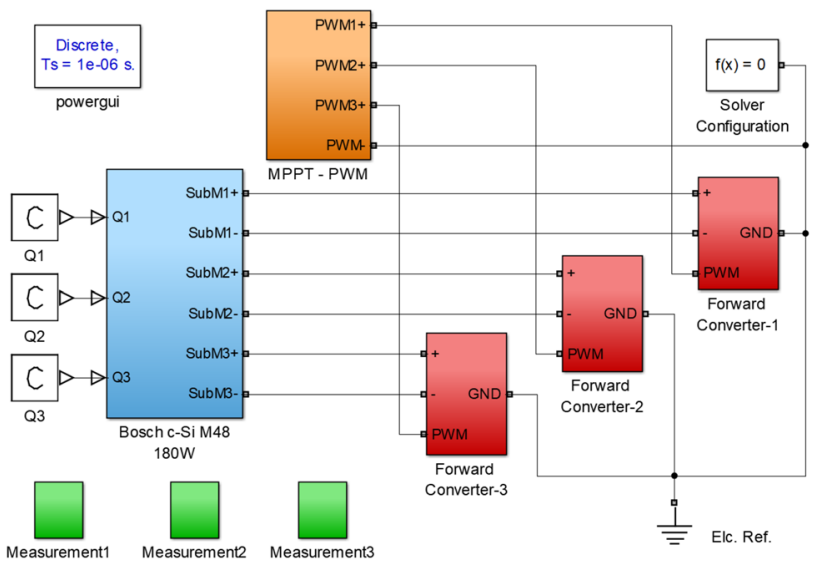

Fig. 4 Simulink model of submodule-level MPPT approach containing three submodules and three forward converters
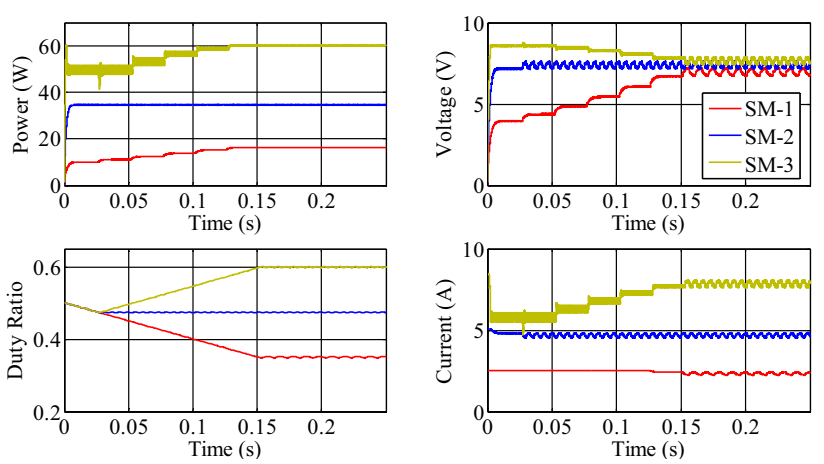

Fig. 5 Simulation results of the submodule (SM)-level MPPT for the first PSC

simulation studies, value of resistors connected in the output of the forward converters is $5 \mathrm{O}$. Initial value of duty ratio is set to $50 \%$, and step value of duty ratio is set to $0.1 \%$. Figure 5 shows the results of the first irradiance profile. As can be seen from the time change in the duty ratio and power in Fig. 5, each submodule tracks MPP in different times. Simulation results show that MPP of the submodule- 2 is tracked firstly by $25 \mathrm{~ms}$ (ms). Then, tracking of MPPs of submodule- 1 and submodule- 3 is carried out in approximately the same period. Tracking time for these MPPs is $150 \mathrm{~ms}$. On the other hand, maximum power values are $16.4 \mathrm{~W}, 34.75 \mathrm{~W}, 60.4 \mathrm{~W}$ for submodule- 1 submodule- 2 and submodule- 3 , respectively. According to the results, three submodules are operated correctly at their MPPs. For this PSC, averaged tracking efficiency in 250 -ms interval is calculated as $93.35 \%$.

In the second shading irradiance profile, values of solar irradiances received by the PV module are $400 \mathrm{~W} /$ $\mathrm{m}^{2}, 700 \mathrm{~W} / \mathrm{m}^{2}$ and $800 \mathrm{~W} / \mathrm{m}^{2}$. Figure 6 shows that tracking is completed firstly by a few $\mathrm{ms}$ in submodule-2. Then, 

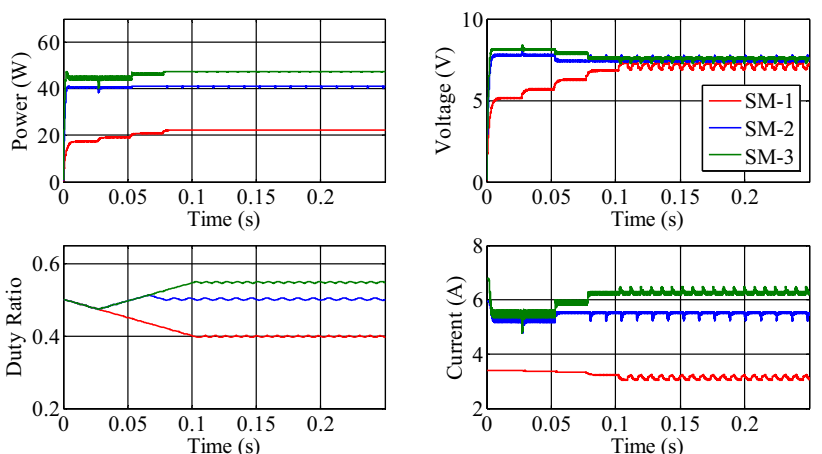

Fig. 6 Simulation results of the submodule (SM)-level MPPT for the second PSC

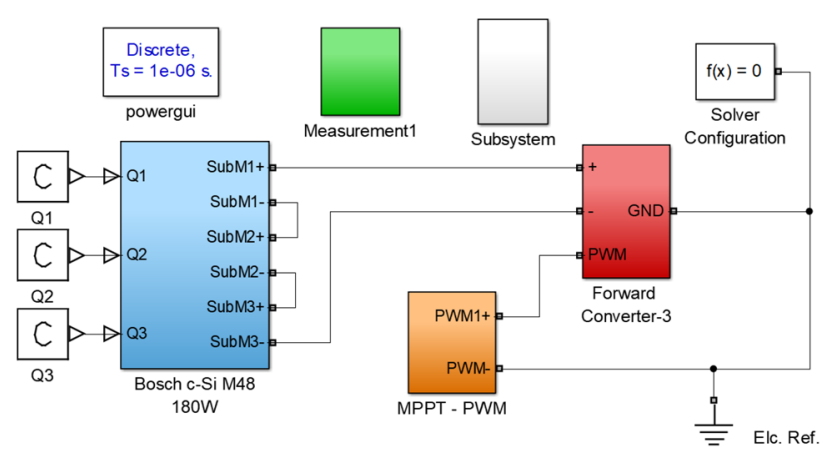

Fig. 7 Simulink model of the module-level MPPT approach

MPPs of submodule- 1 and submodule- 3 are tracked in $100 \mathrm{~ms}$. Maximum power values are $22.4 \mathrm{~W}, 41.1 \mathrm{~W}$ and 47.46 W for submodule-1, submodule- 2 and submodule- 3 , respectively, in this PSC. Since MPPTs are performed independently for each submodule, global MPPT is realized perfectly. Averaged tracking efficiency is $97.34 \%$ for 250 ms interval. Voltage, current and power variations of each submodules are presented in Fig. 6.

In module-level MPPT approach, P-V curve of a PV module containing a few bypass diodes has multi-peak structure. Therefore, $\mathrm{P} \& \mathrm{O}$ algorithm is not generally enough to track global MPP. It can easily fail at local MPP, resulting in small tracking efficiency. On the other hand, available power of a PV module is small compared with the sum of the available power of the submodules which is a disadvantageous condition compared with the submodulelevel MPPT.

Same irradiance profiles are applied to modulelevel MPPT approach. Simulink model used in this test is shown in Fig. 7. In the first irradiance profile (300-600-1000 W/m $\mathrm{m}^{2}$ ), global MPP corresponds to $70.68 \mathrm{~W}$. However, P\&O is failed. Wrong tracking can be seen in the power variations in Fig. 8. Maximum
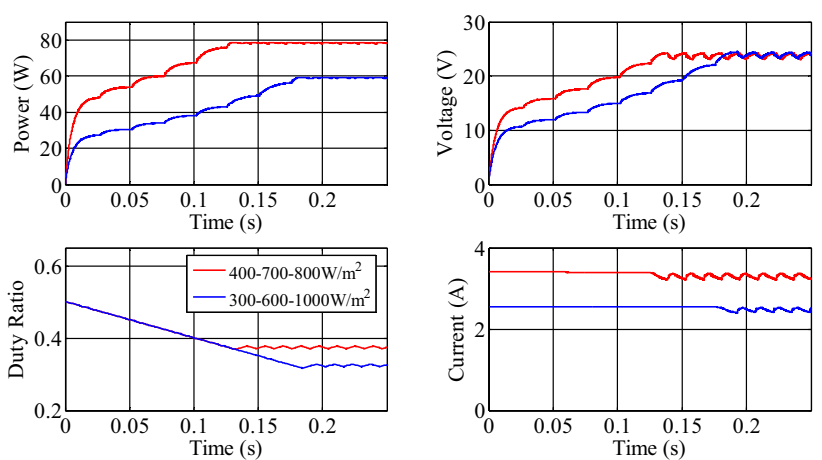

Fig. 8 Simulation results of the module-level MPPT for two PSCs

Table 3 Numerical results of simulation studies

\begin{tabular}{llll}
\hline Irradiance profile & \multicolumn{3}{l}{ Submodule-level MPPT } \\
\cline { 2 - 4 } & SM-1 & SM-2 & SM-3 \\
\hline $400-700-800 \mathrm{~W} / \mathrm{m}^{2}$ & $94.6 \%$ & $99.28 \%$ & $98.16 \%$ \\
& Average 97.34\% & & \\
$300-600-1000 \mathrm{~W} / \mathrm{m}^{2}$ & $86.94 \%$ & $99.23 \%$ & $93.88 \%$ \\
& Average 93.35\% & & \\
\hline Irradiance profile & Module-level MPPT & \\
\hline $400-700-800 \mathrm{~W} / \mathrm{m}^{2}$ & $85.77 \%$ & & \\
$300-600-1000 \mathrm{~W} / \mathrm{m}^{2}$ & $62.36 \%$ & & \\
\hline
\end{tabular}

extracted power is $59.2 \mathrm{~W}$ which is small by $16 \%$ compared with the maximum power value for this profile. Tracking efficiency is calculated as $62.36 \%$ in the $250-\mathrm{ms}$ interval. In the second irradiance profile, global MPP is not tracked by P\&O. Tracking efficiency is $85.77 \%$ in the 250-ms interval for this case. All simulation results are listed in Table 3.

\section{Conclusions}

PV modules can experience some mismatching conditions which decrease available power. MPPT operation can fail at local MPPs, resulting in small tracking efficiency. Partial shading is one of them. PV modules suffer from this mismatching case. In this paper, design, analyses and MPPT performances of a forward converter have been presented for module-level and submodule-level MPPT approaches which can be found in PV power optimizers in the market. Simulation results show that global MPPT is not performed by P\&O algorithm for module-level MPPT. Hybrid and more complicated algorithm requires, since multi-peak structure is seen 
P-V curve under PSCs. On the other hand, global MPPT can be accurately performed by a simple algorithm for submodule MPPT approach. While module-level MPPT tracks the MPP wrongly by $74.07 \%$ efficiency, tracking of MPP is completed by $95.34 \%$ efficiency in submodulelevel MPPT technique.

\section{Compliance with ethical standards}

Conflict of interest The authors declare that they have no competing interests.

\section{References}

1. Başoğlu ME (2019) An improved $0.8 V_{\text {OC }}$ model based GMPPT technique for module level photovoltaic power optimizers. IEEE Trans Ind Appl 55(2):1913-1921

2. Esram T, Chapman PL (2007) Comparison of photovoltaic array maximum power point tracking techniques. IEEE Trans Energy Convers 22(2):439-449

3. Başoğlu ME (2018) An enhanced scanning-based MPPT approach for DMPPT systems. Int J Electron 105(12):2066-2081

4. Başoğlu ME, Çakır B (2018) Hybrid global maximum power point tracking approach for photovoltaic power optimisers. IET Renew Power Gener 22(8):875-892

5. Meneses D, Garcia O, Alou P, Oliver JA, Cobos JA (2015) Gridconnected forward microinverter with primary-parallel secondary-series transformer. IEEE Trans Power Electron 30(9):4819-4830

6. Meneses D, Garcia O, Alou P, Oliver JA, Prieto R, Cobos JA (2012) Single-stage grid-connected forward microinverter with constant off-time boundary mode control. In: 27th annual IEEE applied power electronics conference and exposition (APEC), p 568

7. Liao C, Chen Y, Lin W (2013) Forward-type micro-inverter with power decoupling. In: 23th annual IEEE applied power electronics conference and exposition (APEC), p 2852
8. Kan J, Wu Y, Yao Z (2017) A flexible topology converter for photovoltaic micro-inverter. In: 20th international conference on electrical machines and systems, $\mathrm{p} 1$

9. Hejin Y, Wu P, Youyi W (2015) Design issues for the active clamp forward converter in micro-inverter applications. In: 6th international symposium on power electronics for distributed generation systems, $p 1$

10. Moral D, Barrado A, Lazaro A, Fernandez C, Zumel P (2015) High efficiency DC-DC autotransformer forward-flyback converter for DMPPT architectures in solar plants. In: 9th international conference on compatibility and power electronics, $p$ 431

11. Kuo Y, Tsai C, Kuo Y, Pai N, Luo Y (2014) An active-clamp forward converter with a current-doubler circuit for photovoltaic energy conversion. In: International conference on information science, electronics and electrical engineering, p 513

12. Lee C, Kim J, Park J (2016) Charge balancing PV system using charge-pumped flyback-boost-forward converter including differential power processor. In: 8th international power electronics and motion control conference, $\mathrm{p} 1$

13. Shen C, Tsai C, Wu Y, Chen C (2009) A modified forward multiinput power converter for solar energy and wind power generation. In: International conference on power electronics and drive systems, $\mathrm{p} 631$

14. Lind A (2013) Forward converter design notes. Infineon Technologies, Neubiberg

15. Hart DW (2011) Power electronics. McGraw-Hill, Newyork

16. Başoğlu ME, Çakır B (2016) Comparisons of MPPT performances of isolated and non-isolated DC-DC converters by using a new approach. Renew Sustain Energy Rev 60:1100-1113

17. Nayak B, Mohapatra A, Mohanty KB (2017) Selection criteria of dc-dc converter and control variable for MPPT of PV system utilized in heating and cooking applications. Cogent Eng 4:1-16

18. Bosch PV Module c-Si M 48 datasheet. https://www.solarchoic e.net.au/wp-content/uploads/Bosch-Solar-Module-c-Si-M-48. pdf

Publisher's Note Springer Nature remains neutral with regard to jurisdictional claims in published maps and institutional affiliations. 